\title{
Neoconservadurismo, contramovimientos y estrategias para posicionar la agenda antifeminista. El caso de VOX en España
}

\author{
Neoconservatism, countermovements and strategies to \\ position the anti-feminist agenda. The case of VOX in Spain
}

\author{
HELENA VARELA GUINot \\ Universidad Iberoamericana Ciudad de México \\ Red de Politólogas - \#NoSinMujeres
}

ORCID ID: 0000-0002-2166-2316

Recibido: $24 / 8 / 2020$

Aceptado: $4 / 2 / 2021$

doi: https://doi.org/10.20318/femeris.2021.6406

\begin{abstract}
Resumen. En contraste con un discurso "políticamente correcto" que reconoce la igualdad de derechos entre hombres y mujeres, y con los avances logrados en la legislación de los diferentes países, hay sectores en nuestra sociedad que han denostado y desprestigiado el hecho de ser feminista y que han atacado algunas de las principales banderas del movimiento, como es el caso de la violencia de género o la defensa de políticas que promuevan una igualdad sustantiva entre hombres y mujeres.

El objetivo de este trabajo es analizar este tipo de manifestaciones en contra de la agenda feminista como un movimiento de carácter neoconservador, con una lógica y una forma de actuación específica. A partir del concepto de reacción de Susan Faludi y de las propuestas de análisis de los contramovimientos de Meyer y Staggenborg, y Dillard, se analizan los mecanismos con los que las corrientes conservadoras están construyendo un discurso que cuestiona de manera directa las demandas del feminismo.

Para ello se parte de la propuesta de acción planteada en el Manifiesto del grupo Agenda Europa y se examina el caso de VOX en España. Se hace un análisis del discurso que se ha articulado desde el partido (con el protagonismo de una de sus representantes más emblemáticas, Rocío Monasterio, presidenta de Vox Madrid), para ejemplificar las estrategias adoptadas y la manera en que se ha conformado un contramovimiento, con una agenda antifeminista, que ha logrado calar en sectores importantes de la sociedad española.

Palabras clave: contramovimiento, conservadurismo, antifeminismo.
\end{abstract}

Abstract. LWhereas there is a "politically correct" discourse that recognizes equal rights between men and women, and there have been advances in the legislation of different countries, there are sectors in our society that have reviled and discredited the fact of being a feminist and that have attacked some of the main principles of the movement, such as gender violence, or the defense of policies that promote substantive equality between men and women.

The objective of this work is to analyze this type of demonstration against the feminist agenda as an ultra-conservative movement, with a specific logic and form of action. Based on

*helena.varela@ibero.mx 
the concept of reaction by Susan Faludi and the proposals for the analysis of counter movements by Meyer and Staggenborg, and Dillard, we analyze the mechanisms with which conservative groups are articulating a discourse that directly questions the demands of feminism.

We start from the Agenda Europe document, where a line of action is established, and review the case of VOX in Spain. We use the technique of discourse analysis, to study how it has been articulated from the party (with the leading role of one of its most emblematic representatives, Rocío Monasterio, president of VOX Madrid), and to exemplify the strategies adopted and the way in which a counter-movement has been formed, with an anti-feminist agenda, which has managed to penetrate important sectors of Spanish society.

Keywords: countermovement, conservatism, antifeminism

\section{Las dos caras de una misma realidad}

Frente a los avances logrados en la legislación de muchos países y a un discurso "políticamente correcto" que reconoce la igualdad de derechos entre hombres y mujeres, hay opiniones en nuestra sociedad que han denostado el hecho de ser feminista y que han atacado algunas de las principales banderas del movimiento. No se trata de dos fenómenos distintos, sino que más bien estamos ante una realidad compleja y diversa, en donde las diferentes voces dan cuenta de que el camino hacia la eliminación del sistema patriarcal basado en relaciones de dominación está plagado de obstáculos que no siempre son fáciles de sortear. Llama la atención la cantidad de declaraciones que hoy en día se pueden recabar, que ponen en entredicho los logros derivados de los movimientos feministas. No es que dichas voces sean generalizables al conjunto de la sociedad, pero sí muestran las fricciones que se están presentando en las sociedades occidentales del siglo XXI.

Así, por ejemplo, el reconocimiento de la igualdad formal entre hombres y mujeres, que se refleja en la mayoría de las legislaciones y en la mayor presencia de las mujeres en los espacios públicos, contrasta con la desigualdad sustantiva y de oportunidades, así como con otras formas de discriminación que impiden que las mujeres sobrepasen ese techo de cristal, o incluso, como señalan Martínez y Burgueño (2019), muchas ni siquiera puedan despegarse de los "suelos pegajosos", derivados del entorno de precarización y marginación en que se encuentran. Además, esa mayor presencia en la esfera pública se ha dado muchas veces en contextos de violencia y hostigamiento, con ataques e insultos que poco tienen que ver con su posición ideológica o con su quehacer en la política, y mucho con su condición de ser mujeres ${ }^{1}$.

Un contraste similar nos encontramos con el tema de la interrupción legal del embarazo. Si bien en los últimos años creció de manera significativa la llamada "marea verde" de la lucha por la despenalización del aborto, también han sido importantes los movimientos de la "marea azul", que han tomado las calles alzando las voces en contra de ello, culpabilizando a las mujeres que reivindican el derecho a decidir sobre su propio cuerpo:

\footnotetext{
${ }^{1}$ Ejemplos de este tipo de declaraciones son las del secretario de Organización del PSOE de Huelva, Jesús Fernández Ferrera, cuando en marzo de 2013, le dijo a la entonces ministra de Empleo, Fátima Báñez, que estaría mejor en su pueblo natal, "haciendo punto de cruz" que en el Gobierno (El Mundo, 4 de marzo de 2013); o cuando el concejal de Palafolls, Oscar Bermán, en marzo de 2016 increpó a la alcaldesa de Barcelona, Ana Colau, diciéndole "En una sociedad seria y sana estaría limpiando suelos y no de alcaldesa de Barcelona” (La Vanguardia, 16 de marzo de 2016).
} 
"Las mujeres, en lugar de pedir la despenalización del aborto, 'primero no deberían de abrir las piernas'”, señalaba Héctor Alonso Granados, un diputado local de Puebla, México (Sin Embargo, 30 de mayo de 2019).

Esta doble cara de una misma realidad se observa también en el tema de la violencia de género. Así, después de un largo proceso de ir desnormalizando o desnaturalizando la violencia contra las mujeres, haciéndola visible al sacarla del ámbito privado y ubicarla en la esfera pública, en la actualidad están cobrando cada vez más fuerza los argumentos que refutan el fenómeno, minimizándolo hasta el extremo de la campaña que se lanzó en España en contra de las "feminazis" ${ }^{2}$. Tesis como que la violencia de género no es un fenómeno tan extendido, pues hay muchas acusaciones falsas, o que también hay violencia contra los hombres, o que, en cualquier caso, muchas veces son las mujeres las que provocan la violencia, dan cuenta de esta reacción en contra, como se refleja en algunas declaraciones de la clase política en diferentes partes del mundo:

Mauricio Macri (jefe de gobierno de Ciudad de Buenos Aires): "En el fondo, a todas las mujeres les gusta un piropo. Aquellas que dicen que no, que se ofenden, no les creo nada. No puede haber nada más lindo, por más que esté acompañada de una grosería, así, que te digan, 'qué lindo culo que tenés'.' (La Nación, 22 de abril de 2014).

Pablo Lorenzini (diputado en Colombia): "Hay miles de casos de mujeres que tienen violaciones porque, a lo mejor, tomaron un traguito de más o estaban apenadas, o por las circunstancias que pasan en la vida, que el hombre es muy hábil y las convenció y ella no quería, en ese caso ¿es violación también?” (La Segunda Online, 6 de febrero de 2015).

Ulises Murguía (diputado federal en México): "Es muy importante que cambiemos el tema de ponerle feminicidio a todas aquellas muertes que se dan en nuestras compañeras mujeres, compañeras damas, es simplemente un homicidio, estamos creciendo en los homicidios en México día con día". Consideró que sí se aplica el "feminicidio" para describir una muerte violenta de mujer, también debería de tipificarse el "hombricidio" (Alarcón, 2019).

En tiempos recientes, cada vez están cobrando más peso las posturas que se declaran en contra del feminismo como movimiento y se posicionan abiertamente en contra de la agenda de género que reivindica una igualdad sustantiva entre hombres y mujeres. Además, estos grupos están logrando permear en esferas de gobierno, con el consiguiente impacto en términos de política pública y de acciones gubernamentales en favor de los derechos de las mujeres. Un ejemplo de ello se dio en enero de 2019, cuando el partido de ultraderecha VOX, cuyos votos eran fundamentales para que la coalición del Partido Popular (PP) y Ciudadanos pudiera formar gobierno en la comunidad autónoma de Andalucía, condicionó su apoyo, pidiendo que se eliminara "el punto de acuerdo programático en el que se comprometen a implementar con dotación presupuestaria suficiente todas las me-

\footnotetext{
${ }^{2}$ La asociación HazteOir.org realizó una campaña en febrero de 2019, con la cual se pretendía hacer luchar contra el feminismo radical, pidiendo a los líderes del Partido Popular, de VOX y de Ciudadanos, que "se comprometan a derogar las leyes de género (ley de violencia de género, ley de igualdad de género y las leyes LGTBI)" (ABC, 2019). El hecho de que el lema de la campaña fuera "No es violencia de género, es violencia doméstica", y que se utilizara la imagen de Hitler para denunciar lo que se consideran como excesos de los movimientos feministas, dan cuenta del posicionamiento de este tipo de organizaciones con respecto a la problemática.
} 
didas incluidas en la ley de prevención y protección integral contra la violencia de género" (HuffPost, 2019). Si bien se logró formar la coalición sin que se llegara a adoptar este acuerdo, el desafío planteado pone en evidencia el tipo de discurso que está permeando en diferentes sectores de la sociedad, y que se articula a partir de la descalificación de todas las propuestas que buscan atender el problema de la violencia de género. Así, en esas mismas fechas, el líder de VOX, Francisco Serrano, pedía "fiscalizar los 2200 chiringuitos de género" en Andalucía, con declaraciones del tipo: "Al hilo de la violencia de género se esconde una industria feminista que comercia con su ideología, son un lobby que vive de las subvenciones pagadas con nuestros impuestos y que hay que fiscalizar" (Maestre, 2019).

Pudieran interpretarse los ejemplos anteriores como un conjunto de declaraciones aisladas, sin ninguna relación entre sí. Sin embargo, en esta investigación se sostiene que las manifestaciones en contra de las reivindicaciones que se plantean con una perspectiva de género responden a una situación de corte más estructural, relacionada con la preservación del sistema patriarcal, y que se articulan como un contramovimiento. El objetivo de este trabajo es analizar las características (su lógica y la forma de actuación) de este tipo de manifestaciones en contra de la agenda feminista. ¿Cuáles son los mecanismos con los que las corrientes conservadoras están construyendo un discurso que cuestiona de manera directa las demandas del feminismo? ¿Existe una estrategia específica que permite identificar este tipo de acciones como parte de un contramovimiento?

Para dar respuesta a este interrogante, en un primer apartado, se analizará el neoconservadurismo y su relación con la crisis de la modernidad, lo cual nos permitirá ubicar algunos de los aspectos más importantes de su posicionamiento en relación con la agenda de género. Posteriormente, a partir de las categorías de "reacción" (Faludi, 1993) y de "contramovimiento" en Meyer y Staggenborg (1996) y Dillard (2013), se determinarán las características del discurso sobre género y la violencia de género derivado de las corrientes conservadoras del siglo XXI, que a su vez emanan del documento "Agenda Europa, restaurar el orden natural", mismo que será analizado en el siguiente apartado. Posteriormente, se toma el caso de VOX en España, y se hará un análisis del discurso que se ha articulado desde el partido (con el protagonismo de una de sus representantes más emblemáticas, Rocío Monasterio, presidenta de Vox Madrid), para ejemplificar las estrategias adoptadas y la manera en que se ha conformado una agenda antifeminista, que ha logrado calar en sectores importantes de la sociedad española.

El presente trabajo es un primer paso de una investigación más extensa que busca caracterizar y comparar las manifestaciones en contra del feminismo. La relevancia del objeto de estudio radica en entender y profundizar en las características de movimientos conservadores en el siglo XXI que buscan a toda costa sostener el patriarcado.

\section{Las corrientes neoconservadoras frente a la crisis de la modernidad}

La agenda conservadora sobre temas de género ha logrado avances sustantivos tanto en Europa como en América, tal y como se ha puesto en evidencia en procesos electorales 
recientes. Es importante tener en cuenta que el discurso antifeminista no es exclusivo de la extrema derecha, aunque ésta sea mucho más explícita en sus manifestaciones. Desde otros espacios se observa cómo se ha ido construyendo un discurso muy conservador en torno a estos temas, que busca descalificar y desacreditar movimientos como los feministas o los del colectivo LGBTTI.

Neoconservadores, teoconservadores, ultraconservadores, son algunos de los conceptos que se han utilizado para referirse a estas corrientes de pensamiento. No son nuevas (algunos grupos se remontan a los años ochenta del siglo pasado) y tampoco son uniformes (no es lo mismo el conservadurismo estadounidense, ligado a grupos evangélicos, que las corrientes que han surgido en España o en Francia), pero quisiera rescatar algunos de sus rasgos más característicos, que nos pueden ayudar a entender lo que está ocurriendo con la agenda de género.

Un aspecto importante que hay que considerar es la relación entre estos movimientos de carácter conservador y lo que en ciertos círculos se ha denominado como la crisis de la modernidad. La modernidad puso en el centro al ser humano y a la razón, por encima de cualquier creencia religiosa. Se consideraba que el hombre era capaz de controlar la naturaleza, y que, a partir de sus acciones, era posible someter las diferentes fuerzas para poder tener el dominio del orden social: secularización, racionalidad, republicanismo, industrialización son fenómenos derivados de la idea de modernidad. Se construye, así, un ideal de sociedad, con el ser humano como motor de desarrollo, capaz de promover la igualdad y la libertad. No es la creencia, sino la razón, la que permite este tipo de procesos.

Sin embargo, la realidad acabó distando mucho de ese ideal de sociedad armoniosa, justa e igualitaria. Aunque el discurso se mantenía en esos términos, las contradicciones comenzaron a salir a la luz: la idea de hombre racional y libre no logró evitar los intercambios desiguales y las asimetrías que perpetuaban estructuras de dominación. El gran sueño de un mundo más libre, más igual, con más oportunidades, más democrático, no encontró la manera de materializarse: la libertad era sólo para unos pocos, las desigualdades eran cada vez más lacerantes, una parte del mundo se seguía muriendo de hambre o de enfermedades que podían ser fácilmente atendibles, la exclusión seguía siendo un rasgo característico de la mayoría de las sociedades, y la democracia tuvo que adjetivarse (liberal, procedimental, electoral, delegativa, híbrida, etc.) como única manera de sostener su significado. La sensación de crisis estaba presente:

La "modernidad" ha adquirido un carácter implacablemente disparejo y contradictorio: por este lado hay abundancia de material, lo cual produce pobreza y miseria. Por el otro, mayor diversidad y más opciones, pero frecuentemente a costo de la mercantilización, la fragmentación y el aislamiento. Mayores oportunidades para la participación, pero solo a cambio de que uno se subordine a las leyes del mercado. Novedad e innovación, pero impulsadas por lo que muchas veces parecen necesidades falsas. El "Occidente" rico y el Sur gravemente afectado por hambruna. Formas de "desarrollo" que destruyen más de lo que construyen (Hall, 2014: p.536). 
Estas contradicciones trajeron consigo el desencanto y el escepticismo con respecto a lo que podía esperarse de la llamada modernidad. Resultó que la racionalidad no fue tan eficaz para controlar el orden social o el de la naturaleza. En lugar de armonía, prevalecieron las convulsiones, y se entró en un estado de crisis que cuestionaba la propia forma de entender el mundo. Como resultado de ello, se produjeron varias reacciones, entre las que destaca la denominada "postmodernidad", que se conformó como una reacción directa contra el pensamiento dominante de la Ilustración, al declarar que "nada puede saberse con certeza" (Giddens, 1990: p.52).

Desde la perspectiva del pensamiento postmoderno, la situación de crisis que se vive en la actualidad "es una cierta forma de pensamiento global, omniabarcativo, con pretensiones de universalidad, ordenador del mundo, homogeneizador de las diferencias y del particularismo, en nombre de una supuesta superioridad racional de lo general" (Del Águila, 2002: p.63). Todo comienza a ponerse en duda, a matizarse. Frente a las tendencias generalizantes de la modernidad y las "grandes narrativas" de la modernidad surgen nuevas corrientes de pensamiento que reivindican lo particular, los pequeños relatos, los proyectos pensados para una determinada realidad y un determinado momento. En contraste con la fiabilidad de los sistemas abstractos de la que hablaba Giddens, la postmodernidad "propugna la desconfianza, la actitud desengañada y la distancia escéptica ante ella" (Mardones,1996: p.26).

Los efectos de esta forma de pensamiento fueron importantes, especialmente para aquellos grupos más conservadores, adversos a la incertidumbre y a lo que no se puede controlar. No debe perderse de vista que desde el conservadurismo se manifiesta una total aversión al riesgo y a lo que queda fuera de control:

Ser conservador consiste, por tanto, en preferir lo familiar a lo desconocido, lo contrastado a lo no probado, los hechos al misterio, lo real a lo posible, lo limitado a lo ilimitado, lo cercano a lo distante, lo suficiente a lo superpabundante, lo conveniente a lo perfecto, la felicidad presente a la dicha utópica (Oakeshott, 2007: p.43).

El pensamiento conservador, en su búsqueda de orden y seguridad, no encaja en las corrientes postmodernas, queda como pez fuera del agua. Es por ello, que, desde este talante, se indagan otras vías para lidiar con la crisis de la modernidad, que no pasen por el cuestionamiento de cualquier certidumbre. En esta línea podemos ubicar el neconservadurismo, que hace todos sus planteamientos dejando a salvo el capitalismo, partiendo tanto de "sus ventajas como de sus peligros" (Frachon y Vernet, 2006: p.76). Esta corriente centra su propuesta de cambio, no en los aspectos económicos y sociales, sino fundamentalmente en los culturales. Desde el punto de vista de los neoconservadores, las contradicciones de la modernidad son resultado de un desajuste entre los supuestos del orden político y social, y el conjunto de valores sobre los que se construye dicho orden. La crisis que se está viviendo no es tanto una crisis política o económica, sino que es fundamentalmente una crisis de valores (Mardones, 1996: pp.26-27).

Ésta es una cuestión primordial para entender el tipo de propuestas que surgieron como respuesta a la crisis de la modernidad que se hacen desde el neoconservadurismo. 
Si el peligro radica en el ámbito cultural, entonces la solución tendrá que venir desde esta esfera, y las propuestas de un nuevo orden social se construirán a partir de la reivindicación de una serie de valores que se consideran clave para lograr una sociedad armoniosa. La única manera de encarar la crisis espiritual es vía "fortalecer las estructuras intermedias donde se recrean los valores y se reproduce la transmisión de los mismos. Aquí hay que pensar en la familia, en la escuela, en la parroquia, en las asociaciones voluntarias" (Mardones, 2005: p.420). En contraste con otras etapas, en las que la propuesta conservadora se centró mucho más en el modelo socioeconómico (defensa del neoliberalismo) o político (defensa de la democracia liberal), ahora la cuestión de los valores se constituye en el eje articulador de un discurso y de un modelo de sociedad. Indudablemente, como analizaremos más adelante, esta forma de pensamiento tendrá un impacto directo sobre la agenda de género, cuando la defensa de la familia tradicional se erige en uno de los propósitos de este tipo de movimientos: "Frente a la hegemonía neoliberal para muchos sólo queda el refugio familiar o moral” (Carmona, García y Sánchez, 2012: p.205), aunque esto no sea para confrontar al neoliberalismo, sino, para no tener que entrar en el debate sobre su impacto negativo.

\section{Dos conceptos clave: reacción y contramovimiento}

La reivindicación de los valores tradicionales, y de las instituciones que promueven dichos valores (como es el caso de la familia) propició una corriente de pensamiento que denostaba y cuestionaba todos los avances que se habían logrado en materia de igualdad de género. En este apartado, analizaremos dos conceptos (el de reacción y el de contramovimiento), para explicar la manera en que los movimientos conservadores han respondido a dichos avances y han venido ganando terreno.

En los años noventa, Susan Faludi apuntó, en su obra Reacción. La guerra no declarada contra la mujer moderna (Faludi, 1993), que cada vez que se lograba avanzar en materia de los derechos de las mujeres, se producía una reacción en contra que cuestionaba los logros y reivindicaba una vuelta a los tiempos pasados, una exaltación de la feminidad y todo aquello que mantenía a la mujer en una posición subordinada. Los cuestionamientos partían de aquellos aspectos que habían constituido una mejora en las condiciones de vida de las mujeres, y resaltaban sus impactos negativos, los efectos que habían traído consigo, y que habían acabado resultando más contraproducentes. Lo interesante es que, a través de este tipo de planteamientos, no se negaban de forma explícita los derechos de las mujeres, pero sí la manera en que se estaba concibiendo la lucha por su defensa, pues se consideraba que ésta estaba teniendo un impacto negativo, contrario a lo que se proponía 3 .

Sin entrar en la falacia de los argumentos empleados -que la propia Faludi pone en evidencia- llama la atención la manera en que se han ido construyendo discursos encami-

\footnotetext{
${ }^{3}$ Se esgrimía, por ejemplo, que la incorporación de las mujeres a la vida laboral no estaba permitiendo una verdadera liberación de las mujeres, sino que estaba provocando que éstas fueran más infelices, que se incrementara la tasa de divorcios, e incluso aumentara la esterilidad.
} 
nados a descalificar la lucha por la igualdad de las mujeres, a partir de "presentar a las feministas como espíritus malévolos capaces de provocar grandes males" (Faludi, 1993: p.290).

Este tipo de reacciones se acentúan en los momentos en que se observa un escenario propicio para poder avanzar en materia de reconocimiento de los derechos humanos de las mujeres; es precisamente el temor a lo que puede significar reducir los espacios de dominación, achicar el territorio de conquista sobre los cuerpos de las mujeres, lo que provoca un repliegue por quienes sienten la amenaza y una contraofensiva con el fin de frenar el embate: "La reacción antifeminista no se desencadenó porque las mujeres hubieran conseguido plena igualdad con los hombres, sino porque parecía posible que llegaran a conseguirla. Es un golpe anticipado que detiene a las mujeres mucho antes de que lleguen a la meta" (Faludi, 1993: p.21).

Puede haber variaciones en el discurso, en los actores involucrados, o en el papel que jueguen, por ejemplo, los medios de comunicación, pero existe un patrón que se repite de manera consistente, de tal manera que los avances feministas siempre han venido acompañados de movimientos en contra, que justamente tratan de descalificar y desacreditar lo defendido por dichos movimientos, incluso hasta "conseguir que cierto número de mujeres se vuelvan contra la propia causa" (Faludi, 1993: p.19). Para ello, incluso, se recurrió a mujeres como intermediarias para hacer llegar los mensajes (mucho más potentes que si eran esgrimidos por hombres): "cuando querían tirar una piedra verbal particularmente contra las feministas, se escondían tras una mujer partidaria de la nueva derecha" (Faludi, 1993: p.299). Posteriormente, regresaremos sobre este tema del papel jugado por las mujeres desde el neoconservadurismo, para el caso específico de VOX.

Los medios de comunicación han sido actores clave para la propagación de las corrientes conservadoras, al focalizar la atención en ciertos temas e invisibilizar otros. Así, la raíz del problema se sigue viendo en el movimiento feminista, y no en aquello que hizo necesario dicho movimiento. En las argumentaciones, parece más importante la manera en que pueden ser agraviados algunos hombres que el hecho de que las mujeres lo estén siendo de manera persistente; y es justo esa amenaza a lo que representa la masculinidad la que provoca el tipo de reacciones que señala Faludi: "En cada uno de los períodos de reacción que se han sucedido durante el último siglo, se ha asistido al surgimiento de una «crisis de la masculinidad» que ha acompañado, fiel y silenciosa, a las estentóreas llamadas a la "vuelta a la feminidad»" (Faludi, 1993: pp.96-97).

Se trata de movimientos reactivos, conservadores, porque aspiran a mantener el statu quo, porque, aunque utilizan el argumento de que se preocupan por el bienestar de las mujeres. En realidad, es una forma de disfrazar o simular la necesidad de no alterar el orden establecido, de mantener las relaciones de dominación existentes, y de condenar todo aquello que pone en riesgo dicho orden. No niegan que las mujeres tienen derechos, sino que definen la manera en que estos derechos deben ser ganados y disfrutados, con la excusa de garantizar un equilibrio armónico en las relaciones sociales. La decisión y el control de qué tanto se avanza sigue radicada en la instancia de dominación.

La idea de "reacción" planteada por Susan Faludi nos remite a otro concepto que complementa y ayuda a entender lo que está pasando en nuestros días, y es el concepto de 
contramovimiento. En la misma época que Faludi publicaba su obra, Sidney Tarrow argumentaba en El poder en movimiento. Los movimientos sociales, la acción colectiva y la políti$c a$, que cuando un movimiento "ofende a grupos influyentes", se incrementa la posibilidad de que surjan contramovimientos (Tarrow, 1997: p.174). Éstos son respuestas que surgen como reacción, una contraofensiva frente a los movimientos sociales, que, como una suerte de némesis de éstos, pretende evitar que tengan éxito en el logro de sus objetivos. En esa misma línea, Meyer y Staggenborg, analizaron los factores que propician el desarrollo de los contramovimientos, como son el potencial de éxito del movimiento contra el que se alzan, el grado en el que son amenazados los intereses de ciertos actores clave, y la existencia de aliados políticos que se suman a las movilizaciones (Meyer y Staggenborg, 1996: 1635).

Por su parte, Dillard (2013) identifica la interacción que se produce entre movimientos y contramovimientos, entendiendo estos últimos como respuestas al riesgo que implica el surgimiento de un determinado movimiento social. Uno de los aspectos fundamentales que señala Dillard es que dichos contramovimientos surgen como una forma de reacción por parte de ciertos grupos que sienten sus intereses amenazados. Ante ello, recurren a una serie de dinámicas y estrategias, muchas de las cuales parten del uso de argumentos, lenguaje y actividades extraídas de la propia lógica del movimiento al cual están atacando; esto es lo que Meyer y Staggenborg apuntaban como formas de organización isomórficas (Meyer y Staggenborg, 1996: p.1649). Dillard va un poco más allá al explicar el cambio social a partir de la dialéctica que se establece entre el movimiento y su contraparte, mediante el uso de estructuras, estrategias y tácticas similares, que van encaminadas a desacreditar las propuestas del adversario, desalentar que la gente se sume a su propuesta y convencer a las autoridades para que respalden su punto de vista.

En el caso de los movimientos feministas, podemos establecer una similitud entre los procesos de "reacción" que identifica Faludi y los contramovimientos que señalan Meyer y Staggenborg, así como Dillard. En ambos casos, se parte de una propuesta conservadora, de mantenimiento del statu quo, y de recuperación de las instituciones que salvaguardan los valores tradicionales, lo cual implica el mantenimiento de las estructuras de dominación características del patriarcado. Se articulan, así, estrategias que contrarrestan los avances en materia de igualdad de género, que muchas veces adoptan tácticas y discursos similares a lo que se quiere atacar ${ }^{4}$. Ello ha permitido sostener una estrategia gatopardista de que todo cambia, cuando en realidad lo esencial sigue siendo exactamente igual: "Hoy, el patriarcado tendría más bien la forma de una jaula para ardillas, con una rueda que da la falsa impresión de avanzar cuando, en realidad, se pasa de una posición a otra sin llegar a ninguna parte" (Puleo, 1998: p.51).

A continuación, se analizará cómo se ha gestado y cómo operan los contramovimientos en contra de la agenda de reivindicaciones con perspectiva de género. El supuesto de investigación con el que se trabajó es que existe una estrategia deliberada y organizada para hacer frente al movimiento feminista, que actúa a manera de contramovimiento,

\footnotetext{
${ }^{4}$ Un ejemplo muy claro es lo que se conoce como el posmachismo: "el posmachista adopta una imagen sintómica con la igualdad, marcando incluso distancias respecto al modelo de convivencia patriarcal, pero denuncia hechos puntales que les permiten lanzar una crítica que asegure su posición de dominancia", señala Miguel Llorente en Colomer (2009).
} 
como una reacción en contra de los avances del feminismo y que busca, a partir de repertorios y recursos discursivos emanados del feminismo, debilitarlo y anularlo.

\section{La estrategia. "Restaurar el orden natural: una agenda para Europa"}

Un documento clave para entender las estrategias y tácticas empleadas por los sectores que se han ido alzando en contra del feminismo es el Manifiesto de la Agenda Europa, grupo conformado por una serie de organizaciones ultraconservadores, que se aliaron para luchar en contra de los derechos sexuales y reproductivos ${ }^{5}$. El título del manifiesto hace referencia a la idea de restaurar el orden natural, como la vía para encarar la crisis de valores que está amenazando con destruir la sociedad. Se parte de que hay preceptos morales que no se basan en valores subjetivos, sino que responden a una verdad objetiva (Agenda Europe, s.f.: p.3), y, por tanto, es necesario restaurar un orden legal acorde con el derecho natural. Los apartados a través de los cuales se va hilvanando una narrativa anti feminista son: derecho natural y las ideologías que lo socavan (entre los que se incluye el feminismo y la teoría de género); matrimonio y familia; el derecho a la vida; y el concepto de igualdad. A lo largo de las 144 páginas que conforman el manifiesto quedan recogidos los principales posicionamientos de los sectores más conservadores vinculados a las cuestiones de género, y que pueden entenderse como una reacción (en términos de Faludi) frente a los avances del feminismo.

El último capítulo se dedica a la estrategia que hay que adoptar para lograr posicionar esta agenda. Se diseña una hoja de ruta para responder a la crisis cultural de valores. Para ello, se plantean cinco necesidades básicas que hay que atender: concebir el fenómeno que se está viviendo como una guerra cultural, que para ganarla se requiere pasar de las tácticas defensivas a posiciones proactivas que busquen mellar al adversario (Agenda Europe, s.f.: p.109); entender y aprender de los enemigos; crear redes de apoyo para fortalecer el movimiento; adaptarse al entorno legal y político; y tener un glosario de términos, partiendo de la base de que muchos conceptos han sido tergiversados por quienes han defendido la llamada agenda de género.

Cabe señalar la similitud entre la estrategia que plantea la importancia de conocer al adversario y la táctica que se identificó en el concepto de contramovimiento de utilizar los propios argumentos, el lenguaje o la lógica de los movimientos que se están atacando. Se habla de conocer las organizaciones y los lobbys que conforman las movilizaciones a favor del aborto, la homosexualidad, el feminismo radical y el ateísmo, de identificar las estrategias que emplean estos grupos, para poder contrarrestarlas. Para ello, se propone una serie de tácticas, que incluyen el aprovechar las propias armas de los oponentes para

\footnotetext{
${ }^{5}$ La Agenda Europa surge a partir de 2013, a partir de una serie de activistas estadounidenses y europeos, cuyo objetivo era limitar los derechos humanos relacionados con la salud sexual y reproductiva, derechos de la mujer y del colectivo LGTBI. Más de un centenar de organizaciones muy cercanas al Vaticano, pero no sólo de carácter religioso, han ido armando una agenda a partir de un blog (https://agendaeurope.wordpress.com/), reuniones anuales y un manifiesto (EPF, 2018), aunque desde la página agendaeurope.org se afirma que Agenda Europe Network (http://agendaeurope. org/) no tiene ninguna vinculación con el blog (Agenda Europe Network, 2018).
} 
usarlas en su contra, tal y como lo plantea Dillard en su concepto de contramovimiento. Algunas de las recomendaciones que se dan son:

- Se destaca la importancia de la comunicación como un elemento fundamental a la hora de expresar ideas: no sólo es importante lo que se dice, sino cómo se dice.

- El nicho al cual hay que dirigir el discurso es el de las personas escépticas, aquellas que pueden tener sentimientos ambivalentes o dudas sobre las políticas que se han implementado hasta ahora.

- Una táctica de gran impacto es la de abordar los temas desde una perspectiva de derechos (por ejemplo, el derecho de los padres a decidir la educación de los hijos, o el derecho del no-nato a la vida). De esta manera, se plantea una apropiación del lenguaje de los oponentes y se utiliza para defender una agenda contraria.

- Si los adversarios difunden datos falsos, proveer los datos correctos.

- Utilización de datos, cifras e información que sustente los argumentos y contrarreste los esgrimidos por los adversarios.

- Sensibilizar a la audiencia sobre temas clave, sobre todo cuando son cuestiones que los oponentes rehúyen.

- Desenmascarar el reclamo de los adversarios de ser las víctimas, lo cual incluye una estrategia de difamación, que lleva a afirmaciones como que la violencia es intrínseca a las estrategias de los adversarios (Agenda Europe, s.f.: p. 118).

Lo que refleja este Manifiesto es que las organizaciones ultraconservadoras no están actuando de manera espontánea ni aislada, sino que detrás de las movilizaciones hay un movimiento articulado, con la intención explícita de revertir todos los avances que se han dado en materia de género. Inicialmente, fueron abriendo brechas, que les permitió ir ganando terreno sin llamar excesivamente la atención. Una vez se hicieron con el espacio, comenzaron a actuar, agarrando a contrapié a quienes postulaban ideas contrarias:

El ultraconservador de nuestros días se presenta típicamente como una minoría desvalida que, en realidad, ha alcanzado puestos de representación y ejercicio del poder público para desmantelar todas las estructuras de bienestar y seguridad social, así como los derechos sexuales y reproductivos (Hernández, 2019).

Una vez dentro, es cuando las propuestas comienzan a integrarse y a tomar cuerpo en forma de contramovimiento. Y eso es precisamente lo que está ocurriendo con el tema de la agenda feminista, tal y como lo analizaremos en el siguiente apartado, para el caso de VOX.

\section{VOX y la agenda antifeminista}

El estudio de un caso específico permitirá poner a prueba las categorías de contramovimiento y de reacción que hemos apuntado, vinculadas a las corrientes neoconserva- 
doras, y a las estrategias que están implementando para posicionar una agenda antifeminista. Para ello, se tomó el caso del partido VOX en España, fundado en diciembre de $2013^{6}$ y se realizó un análisis del discurso en torno a la temática de violencia de género. Éste se hizo a partir de la revisión de los documentos oficiales del partido (estatutos, manifiesto fundacional, propuesta de cien medidas), así como de las referencias que en la página del partido se hacen al tema de "ideología de género". Asimismo, se hizo una búsqueda en la red de entrevistas ofrecidas por una de las voces más representativas de esta postura, que es Rocío Monasterio, presidenta de VOX Madrid ${ }^{8}$. A través de análisis de narrativas (Urra, Muñoz y Peña, 2013: p.54), el estudio se centró en la narrativa como discurso, en cómo se articulan las tramas en torno a eventos, con el fin de identificar los rasgos más característicos del discurso, y ver hasta qué punto las categorías de reacción y contramovimiento sirven para explicar la postura del partido con respecto al feminismo.

VOX es un partido político que nace con una bandera ultranacionalista que aboga por un "proyecto político para la renovación y el fortalecimiento de la vida democrática española" desde una agenda claramente conservadora: "Nuestro proyecto se resume en la defensa de España, de la familia y de la vida; en reducir el tamaño del Estado, garantizar la igualdad entre los españoles y expulsar al Gobierno de tu vida privada" (VOX España). Temas clave de su propuesta política son la unidad de España, la inmigración, el cuestionamiento de la Unión Europea y la agenda en defensa de la familia. Nos detendremos en este último caso.

Los estatutos del partido establecen ocho fines que se persiguen, como la defensa de la unidad de la nación española, la defensa de la libertad individual y el estado de derecho, la defensa de la igualdad de todos los españoles ante la ley, la defensa y promoción de la presencia activa de la sociedad civil, la defensa de la propiedad privada y la libre economía de la vida, la defensa del derecho a la vida y la protección de la familia, el fortalecimiento de la posición internacional de España y la defensa del español en todo el territorio español (VOX, Estatutos).

Sin embargo, cuando se revisa la página web del partido, en los apartados de "Manifiesto fundacional", que incluyen "Nuestro Manifiesto", "Razón de ser", "Principios inspiradores" y "Agenda para el cambio", no hay una referencia explícita a una agenda sobre el punto 6, en torno a la defensa a la vida y la protección a la familia; salvo alusiones generales, los asuntos de género se omitieron de forma clara y formal, por lo menos inicialmente. En cambio, las referencias a temas de género se encuentran fundamentalmente en declaraciones de sus representantes en medios de comunicación, o en videos que abordan algunos aspectos concretos y van construyendo el discurso antifeminista, tan característico de este partido.

\footnotetext{
${ }^{6}$ Algunos textos sobre el partido VOX, que dan cuenta de sus orígenes y de su agenda programática son González Cuevas (2019), Urbán (2019) o Fernández Vázquez (2019).

${ }^{7}$ Para entender el concepto de "ideología de género" y su vinculación con los sectores más conservadores, ver Cornejo-Valle y Pichardo (2017).

${ }^{8}$ Se ha dejado fuera del análisis el texto de Alicia Rubio (2017), Cuando nos prohibieron ser mujeres... y os persiguieron por ser hombres. Para entender cómo nos afecta la ideología de género, porque no aparece como una postura oficial del partido, aunque los planteamientos sean los mismos.
} 
Formalmente, fue hasta octubre de 2018 , que el partido dio a conocer las "100 medidas para la España Viva", en donde aparece un apartado específico sobre "Vida y familia", que presenta doce propuestas (de la 70 a la 81):

70. Derogación ley de violencia de género y de toda norma que discrimine a un sexo de otro. En su lugar, promulgar una ley de violencia intrafamiliar que proteja por igual a ancianos, hombres, mujeres y niños. Supresión de organismos feministas radicales subvencionados, persecución efectiva de denuncias falsas. Protección del menor en los procesos de divorcio.

71. Creación de un Ministerio de Familia. Promulgación de una ley orgánica de protección de la familia natural que la reconozca como institución anterior al Estado. Buscaremos la todavía lejana convergencia con la media europea en cuanto a prestaciones familiares.

72. Apoyo decidido a las familias numerosas y a la natalidad en general. Creación de cheques servicio que subvencionen parte de las necesidades familiares como los libros escolares, transporte público, etc. Establecer bonificaciones proporcionales al número de miembros de las familias en todo tipo de suministros básicos como luz o gas o el acceso a bienes culturales.

73. Crear y dotar anualmente en los Presupuestos Generales del Estado una prestación universal por hijo a cargo para las familias españolas, por un mínimo de 100 euros al mes. Esta prestación será creciente a partir del tercer hijo y se actualizará anualmente. Serán beneficiarias las mujeres que sean madres, sea cual sea su situación familiar y laboral, y mientras los hijos sean menores de edad si previamente no tienen un trabajo retribuido.

74. Tratar las bajas por enfermedades relacionadas con el embarazo como baja por maternidad, cero coste para la empresa.

75. Defensa de la vida desde la concepción hasta la muerte natural. Es fundamental que las mujeres con embarazo inesperado tengan información veraz, asistencia y alternativas. Reforma de la ley de adopción nacional.

76. El Estado proporcionará una protección especial a la infancia, en sus espacios educativos, recreativos y de comunicación pública. Se restaurará el tipo penal que persiga con más eficacia y dureza la perversión de menores.

77. Conciliación vida familiar y laboral, fomento del teletrabajo y trabajos de media jornada. Fomentar la flexibilidad de horarios e implantar un plan específico de reincorporación, para facilitar que los padres que hayan estado un tiempo dedicados al cuidado de los hijos puedan reincorporarse a la actividad laboral.

78. Ampliar el vigente permiso por maternidad a 180 días que se prolongaría a un año en el caso de hijos con discapacidad.

79. Desarrollo de un plan integración de las personas con síndrome de Down. Tratadas como una condición personal, no una discapacidad, y amparándoles ante la persecución que sufren por parte de quienes se han propuesto exterminarles.

80. Prohibición de los vientres de alquiler y toda actividad que cosifique y utilice como producto de compra venta a los seres humanos.

81. Defensa de la custodia compartida como regla general y proteger el derecho de los menores a relacionarse con ambos progenitores y con sus abuelos. 
La primera de estas medidas resume perfectamente la postura de VOX con respecto a la perspectiva de género en general y la violencia de género en particular, cuyos rasgos más característicos analizaremos a continuación.

En primer lugar, desde la mirada de VOX, las posturas feministas son perniciosas porque han provocado que se discrimine a la mitad de la población. Así, se adopta el discurso del adversario, y se le da la vuelta, señalando que quienes realmente discriminan son las feministas. Los hombres se vuelven víctimas, por lo que todo el discurso basado en la idea del patriarcado como sistema de dominación, pierde su sentido cuando el agresor se convierte en agredido. Para ello, se recurre a lo emocional, a lo más visceral, para poner en evidencia la parte más perversa del feminismo. En la web se puede encontrar un breve video de poco más de un minuto (que forma parte de una entrevista), en donde aparece Rocío Monasterio diciendo lo siguiente:

Tristemente, sigue habiendo todos los años muchas mujeres asesinadas, pero también hay niños y ancianos, que resulta que llaman al 016, y por ser varón les cuelgan el teléfono. Y ese anciano o ese niño de 16 años, que es varón, y que le están pegando en su casa, también, digo yo, tiene derecho a ser protegido de la violencia. Queremos una ley de violencia intrafamiliar, queremos educar a nuestros niños en el respeto, en la igualdad, y no entendemos que los demás políticos se nieguen a todas estas mejoras. Esa es una gran irresponsabilidad. No entendemos por qué no quieren acabar con la violencia y por qué no quieren proteger a ese anciano que llama a un 016 y le cuelgan, y por qué tiene que estar discriminado por el hecho de ser un varón. Eso a mí no me gustaría contarlo a mis hijos. Tengo cuatro, tres niñas y un chico, y no me gustaría contarle a mi hijo que ha nacido en un país en que eres distinto por ser hombre (https://www.youtube.com/watch?v=aA8uV38hNkM).

Primero reconoce la existencia de la violencia contra las mujeres, esto es, articula la narrativa desde la propia trinchera del movimiento que se quiere atacar. Pero a continuación, se descalifica al poner en evidencia sus fallas, y para ello se invoca la imagen de un anciano o un niño que son asesinados, porque, por ser varones, nadie los atendió. A partir de ahí se construye el discurso de lo que se quiere, para, finalmente, acabar con otra imagen que también es muy significativa, la de su propia familia, la de sus hijos, y la frase contundente de "no me gustaría contarle a mi hijo que ha nacido en un país en que eres distinto por ser hombre".

Esta idea de las feministas como las verdaderas enemigas de una convivencia pacífica es reforzada en múltiples espacios, llegando al extremo de una declaración de otra mujer, María Ruiz, integrante del Comité Ejecutivo del partido, que en otro video afirma: "Lo que quieren es que acabemos con los hombres" (https://www.youtube.com/ watch?v=jJfBS1YvYik).

Una vez queda asentado quién es el adversario, en la propuesta de VOX se establece el siguiente punto que define claramente su postura con respecto a los temas de violencia: no podemos hablar de violencia de género, sino, en todo caso, de violencia intrafamiliar. La distinción es crucial, porque al hablar de violencia intrafamiliar se deja de reconocer que 
hay un patrón de dominación basado en las relaciones de poder que legitiman la opresión. VOX reconoce que hay violencia, pero ésta se explica por las circunstancias específicas de determinadas personas, no por la existencia de un sistema patriarcal que propicia estas formas de violencia. Por tanto, esta perspectiva de patologización de la violencia implica que, en lugar de ir a la raíz del problema (sus causas estructurales), basta limitarse a la atención individual de las personas que puedan ejercer la violencia, a través de una propuesta punitiva (con medidas como la de cadena perpetua al agresor).

En la trama narrativa que se va construyendo para descalificar las reivindicaciones feministas en torno a la violencia de género, hay que sumar el tema de las denuncias falsas, que busca convertir a los victimarios en víctimas. Es interesante cómo en este caso se recurre a una de las tácticas formuladas en el Manifiesto de la Agenda Europa, de utilizar las cifras para convencer, y se recurre a la misma estratagema de la que se acusan a los enemigos, de tergiversar dichas cifras: se toman casos aislados de denuncias falsas y se generaliza, diciendo que la mayoría de las acusaciones se basan en falsos testimonios de las mujeres.

Los efectos que una postura así puede tener, en términos de políticas públicas, son devastadores, pues hace desaparecer la problemática de la agenda política, y, por tanto, desde el Estado no es posible esperar las soluciones. Como señala Ana de Miguel: "Hasta que el feminismo no logra redefinir la violencia de 'caso aislado' y 'tragedia personal' como un 'problema público y social' que afecta e implica a toda la sociedad, no es posible formular reivindicaciones políticas concretas" (De Miguel, 2015: p.14).

En esta lógica, si las feministas son personas perversas que quieren acabar con los hombres, si en realidad no existe eso llamado "violencia de género", entonces es necesario eliminar todos los apoyos que reciben las organizaciones feministas, porque éstas sólo merman los recursos del Estado.

Esta es la esencia del discurso antifeminista que se articula desde VOX, y que acaba siendo empaquetado y etiquetado como el discurso contra la "ideología de género", tema que es reforzado con la idea de que se trata de un "adoctrinamiento", una "imposición" que

atenta gravemente contra, por supuesto, la igualdad de los españoles, pero atenta gravemente contra la libertad de los padres a educar a nuestros hijos según nuestros valores, persigue a todo aquel que cuestione esta ideología totalitaria, ataca gravemente contra la libertad, por ejemplo, de los medios de comunicación, a los que obliga a un protocolo, a un lenguaje y a contar esta doctrina. Ataca a la libertad también de nuestros profesores, que no pueden contar un modelo de familia, ataca también la libertad religiosa.

Cuando se revisan las declaraciones de miembros del partido no se va mucho más allá de lo aquí señalado: se trata de un discurso relativamente simple, que el partido resume en cuatro pequeños videos, todos de 2019, que son los que aparecen en el link de "Noticias", en el apartado de "Ideología de género": en el primero, la presidenta de VOX Madrid, Rocío Monasterio, habla sobre el tema del orgullo gay (https://www.voxespana. es/noticias/rocio-monasterio-orgullo-tenemos-exigir-minimo-civismo-respeto-demasrespeto-persona-20190701), y asevera: “Tenemos que exigir un mínimo de civismo, de 
respeto a los demás y de respeto a las personas" (entre otras cosas, arremete contra las marchas señalando que una madre o un padre que salgan de su casa con sus hijos "no tiene por qué encontrarse con ese espectáculo"); otro video de la misma Rocío Monasterio, que se encabeza con la declaración de "Las feministas no quieren oír hablar de las familias" (https://www.voxespana.es/noticias/ideologia-de-genero/rocio-monasteriolas-feministas-no-quieren-oir-hablar-de-las-familias-20190402); un tercero, también con Monasterio, con el título "Celebremos ser mujeres 364 días al año; todos menos el 8 de marzo" (https://www.voxespana.es/noticias/ideologia-de-genero/monasterio-celebramos-ser-mujeres-364-dias-al-ano-todos-menos-el-8-de-marzo-20190305); y una declaración del secretario general de Vox, Javier Ortega Smith, en el sentido de que "Acordarse de las mujeres solo un día al año es no valorarlas" (https://www.voxespana.es/noticias/ ideologia-de-genero/ortega-smith-acordarse-de-las-mujeres-solo-un-dia-al-ano-es-novalorarlas-20190305).

Aquí se analizarán los dos videos de Monasterio que aluden directamente al tema del feminismo. El primero, con una duración de 6 minutos y diez segundos, se desarrolla en una obra en construcción, en donde Rocío Monasterio aparece, haciendo alusión a su profesión de arquitecta, como si estuviera trabajando; la política lleva un casco y, al tiempo que va respondiendo a una serie de preguntas que aparecen escritas en la pantalla, se la ve supervisando la obra y dando instrucciones a hombres que atienden diligentemente a las mismas. Señalamos a continuación algunas de las frases más significativas:

"[A las feministas les diría] "que dejen de utilizar un lenguaje excluyente con las mujeres que no compartimos toda su doctrina, que dejen de querer imponernos a una mayoría de mujeres un discurso único".

"Creemos en la verdadera igualdad".

"Igual que a lo mejor a muchas mujeres no les gustan determinados puestos de responsabilidad porque suponen ver menos a sus hijos y estar menos con su familia. ¿Sabes lo que pasa? Que el parámetro no es siempre el salario para las mujeres, tenemos otras cosas que nos interesan y que valoramos más, como, por ejemplo, es el tiempo con nuestros hijos. Y de eso, las feministas que atacan tanto a la familia, no quieren hablar".

"[El feminismo] es el que defiende la igualdad de hombres y mujeres. Y yo siempre he estado orgullosa del feminismo español, de Concepción Arenal, de Clara de Campoamor y de Emilia Pardo Bazán, de muchas mujeres que sí pelearon y que sí les costó mucho luchar por ganar en derechos (...) Esas mujeres sí que lucharon, pero estas mujeres que hoy se roban y se ponen como voces del feminismo, cuando te estudias su trayectoria te das cuenta de que no han luchado por nada."

Es interesante este video, porque es un claro ejemplo de cómo se emplean los argumentos y los espacios simbólicos del adversario -las feministas- para atacarlas y descalificarlas. En primer lugar, es una mujer la que da el mensaje, y esto nos remite a lo que apuntamos cuando analizamos los conceptos de reacción y de contramovimiento, al señalar que muchas veces se recurre a mujeres para transmitir los mensajes más claramente antifeministas. Además, para reforzar la idea y dar más peso al mensaje, la mujer no ha- 
bla desde su hogar, como ama de casa o madre de sus hijos, sino como una profesionista exitosa, que se mueve cómodamente en un mundo entre hombres, como es el de la construcción. De esta manera, se quiere reforzar la idea de que no se habla desde una postura de sumisión sino de empoderamiento: se auto erige con la "autoridad moral", que puede constatar, con su propia experiencia, que las mujeres han avanzado mucho en nuestra sociedad, y, por tanto, deben dejar a un lado el discurso de corte victimista. Es interesante este planteamiento, pues es una constante en los planteamientos antifeministas: se elude la referencia al conjunto de las mujeres, y se toman los casos individuales de éxito como prueba de que los argumentos esgrimidos no tienen razón de ser.

A partir de ahí va hilvanando una serie de ideas que llevan a la descalificación del feminismo (otra de las estrategias planteadas por la Agenda Europa y que forma parte de lo que Faludi identificaba como una reacción): se parte de un concepto de "verdadera igualdad", redefinido de acuerdo a los propios intereses; es más, en un momento dado del video, se llega a ensalzar el feminismo representado por mujeres como Concepción Arenal, Clara Campoamor o Emilia Pardo Bazán, así como la necesidad de reconocer los derechos de las mujeres. Pero a partir de ahí, se comienza a articular un discurso dicotómico que confronta el feminismo que ella defiende, en contraposición con un feminismo excluyente, doctrinario, que lo único que busca es acabar con la maternidad y con la familia. El concepto de ideología de género está en todo momento presente, como un mecanismo para cuestionar todo lo que representa el movimiento feminista, a partir del vocabulario y los argumentos esgrimidos por éste.

En el segundo video, que lleva por título "Las mujeres de Vox rompen con la huelga feminista del 8M" y tiene una duración de 2 minutos con 59 segundos, Rocío Monasterio aparece rodeada de mujeres, leyendo un comunicado "\#NoEnMiNombre". Simbólicamente lo hace a los pies de una estatua de Concepción Arenal, nuevamente en un guiño hacia el "buen feminismo", en contraposición al feminismo doctrinario. En primer lugar, parte del reconocimiento de los derechos conquistados por las mujeres; al igual que en el video anterior, no está negando que la mujer deba tener igualdad de oportunidades que los hombres, sino que es precisamente ese reconocimiento lo que la lleva a recapacitar y cuestionar el tono impositivo de ciertas feministas; dicho cuestionamiento lo hace desde su propia identidad como mujer, y eso lo hace más significativo y simbólico:

“200 años más tarde en España la mujer tiene todos los derechos reconocidos en la Constitución, y somos iguales, hombres, mujeres, ante la ley, y creemos en defender la verdadera igualdad, con la ley, educando en el respeto entre hombres y mujeres, no adoctrinando la desigualdad. No hables en mi nombre, porque soy mujer, y no soy víctima por el hecho de nacer mujer; soy mujer y el Estado no me tiene que proteger, ni dar, ni quitar, tengo los mismos derechos que el hombre, por ser española."

"Soy mujer y quiero liberarme de vuestro burka ideológico, que pretende imponernos una doctrina totalitaria."

"Soy mujer y no quiero una doctrina que me enfrente al hombre, no quiero que se criminalice al hombre, ni a mi hermano, ni a mi padre, ni a mi hijo, por el hecho de ser varón. 
Soy mujer, y no necesito que el Estado me garantice mi puesto de trabajo con cuotas, ya me lo gano yo. No necesito la condescendencia del hombre ni de las feministas supremacistas."

"Soy mujer y madre, y quiero para mis hijos que se respete su derecho a ser educado sin ser adoctrinado en ideologías totalitarias y anticientíficas como la ideología de género."

"Soy mujer y no quiero que los recursos públicos de los españoles vayan a una agenda política de género que se nos impone desde todas las instituciones."

"Soy mujer y siempre recordaré con orgullo a esas mujeres españolas que nos allanaron el camino, y el 8 de marzo, por eso, no iremos a la huelga. Celebramos ser mujer 364 días al año. Todos, menos el 8 de marzo, que trabajaremos más que nunca para reafirmarnos en el poder de nuestra independencia y nuestra libertad".

El peso que tiene cada afirmación que comienza con la frase "Soy mujer" es muy fuerte, pues es ese "ser mujer" el que nuevamente le da la legitimidad para atacar a las feministas y para distinguir, con una visión maniquea, entre quienes realmente buscan "nuestra independencia y nuestra libertad" y quienes portan un "burka ideológico".

Como se puede apreciar, en ambos casos el patrón es el mismo: es la condición de mujer la que le da la legitimidad para ser crítica con el movimiento feminista, por considerarlo totalitario, doctrinario e impositivo. En otras entrevistas, el discurso es semejante, al poner el énfasis en la ideología de género, por su carácter acientífico y totalitario.

En esa misma línea se ubican otras declaraciones y campañas del partido, como la que se desplegó en marzo de 2019 (\#NoHablesEnMiNombre), o el Manifiesto por el Día Internacional de la Eliminación de la Violencia contra la Mujer (noviembre de 2019). En ambos casos la estrategia ha sido muy similar: son mujeres (Rocío Monasterio, Macarena Olona -Secretaria General del grupo parlamentario de VOX-, y otras legisladoras) quienes presentan ante la opinión pública la postura del partido; para ello, se descalifica al adversario y se aprovecha su discurso y sus lógicas de acción, para volverlas en su contra. Además, esto se hace, siguiendo las recomendaciones de la Agenda Europa, dando una atención primordial a la manera en que se comunica. A pesar de sus contenidos, no se trata de discursos estridentes o beligerantes, sino que el mensaje se da de una manera sosegada, desde una aparente moderación, marcando el contraste entre la violencia del adversario y la serenidad propia. Sin duda, ello ha tenido un impacto entre determinados sectores de la sociedad (los escépticos a los que hace referencia el documento "Restaurar el orden natural"), que han comenzado a cuestionar la pertinencia de políticas públicas con miras a una igualdad sustantiva.

\section{Conclusiones}

A lo largo de este trabajo, se planteó que la idea de contramovimiento está en consonancia con lo que ya Susan Faludi señalaba a principios de los años noventa, como "la guerra no declarada contra la mujer moderna" (Faludi, 1993). La autora señalaba que cada vez que las mujeres lograban avances en su lucha por la igualdad, se desataba una 
corriente en contra que buscaba frenar dichos avances: "Cuando la exigencia femenina de derechos iguales parecía más próxima al logro de sus objetivos, era contrarrestada por la reacción" (Faludi, 1993: p.20). Todo parece indicar que nos encontramos ante una etapa contracíclica, una nueva ola de reacción, y que ello a su vez se liga a las corrientes neoconservadoras que buscan apoyarse en las instituciones tradicionales, como la familia, que permitan la recuperación de los valores sobre los que se sustenta el patriarcado.

Los conceptos de contramovimiento (Meyer y Staggenborg; Dillard) y de reacción (Faludi) conformaron el marco de referencia para el análisis de las manifestaciones antifeministas que se ubican como una reacción en contra de lo que, para algunos sectores de la sociedad, es un cambio demasiado rápido en nuestra sociedad. Desde esta perspectiva, este tipo de contramovimientos irían encaminados a frenar los avances logrados por las mujeres mediante posturas claramente conservadoras que buscarían el mantenimiento del statu quo y el control sobre los procesos de cambio. Un supuesto con el que se trabajó es que detrás de este tipo de reacciones hay una organización y una estrategia deliberada (como se refleja en el documento "Restaurar el orden natural") para anular la agenda de reivindicaciones con perspectiva de género.

Se tomó el caso del partido VOX en España, como un ejemplo de contramovimiento que se da desde la ultra derecha, con un discurso abiertamente descalificador de los feminismos. Con ello, se buscó tener una primera caracterización de este tipo de movilizaciones. Se analizó el tipo de discurso que se articula a partir de una narrativa dicotómica entre el buen y el mal feminismo. Detrás de ello se observa una estrategia deliberada, afín a lo que plantea el Manifiesto de la Agenda Europa, y en consonancia con lo que tanto Meyer y Staggenborg, así como Dillard, entienden como un contramovimiento: se parte del reconocimiento de la idea de fondo que hay en el movimiento social (los derechos de las mujeres), y a partir de ahí se emplea una doble estrategia: la descalificación del adversario (con una visión maniquea de lo que es bueno y lo que es malo) y la construcción de un discurso que resulta atractivo para determinados sectores de la sociedad (sin duda, los hombres que se sienten amenazados por un movimiento que busca acabar con las formas de dominación, pero también grupos de mujeres que se sienten más cómodas en un terreno ya conocido, en donde la sujeción está tan normalizada y que no sienten la necesidad de eliminarla).

Resulta interesante ver cómo está permeando este discurso en contra del movimiento feminista, logrando desviar el centro de atención de aquellos aspectos que el feminismo quiere discutir y cuestionar (las formas de dominación). La mejor manera de debilitar un movimiento es haciendo que no se hable de sus objetivos, sino de las cualidades morales de quien los defiende. Y eso es lo que está haciendo VOX en España. Con un discurso ilusionante (yo les traigo la paz y la alegría, y pido a las feministas...), muy atractivo para los sectores más escépticos de la sociedad, hacen parecer que las erradas son las mujeres que están en los movimientos feministas, mientras que ellos sí defienden el orden natural y la verdadera igualdad.

La coyuntura política nos pone en alerta sobre el terreno que están ganando posturas ideológicas abiertamente xenófobas, antifeministas, homofóbicas o racistas, propiciando 
espacios de exclusión y discriminación; entender este tipo de movimientos se vuelve clave para poder resistir sus impactos.

\section{Referencias bibliográficas}

ABC (2019). Hazteoir vuelve a la carga y pone en circulación un autobús contra el feminismo radical. $A B C, 28$ de febrero de 2019. Disponible en https://www.abc.es/sociedad/abci-hazteoir-vuelve-carga-y-pone-circulacion-autobus-contra-feminismoradical-201902280232_noticia.html

Agenda Europe (s.f.). Restoring de Natural Order. An Agenda for Europe. Disponible en https://agendaeurope.files.wordpress.com/2019/05/rtno-2014.pdf

Agenda Europe Network. (2018). Agenda Europe Position Regarding EPFPD Book on Agenda Europe. Disponible en http://agendaeurope.org/

Alarcón, Juan Carlos. (2019). Diputado morenista minimiza feminicidios; advierte que el término genera terror social. MVS Noticias, 21 de marzo de 2019. Disponible en https://mvsnoticias.com/noticias/nacionales/diputado-morenista-minimiza-feminicidios-advierte-que-el-termino-genera-terror-social/

Carmona, Pablo, García, Beatriz y Sánchez, Almudena. (2012). Spanish Neocon. La revuelta neoconservadora en la derecha española. Madrid: Traficantes de Sueños.

Colomer, Álvaro. (2009). Miguel Llorente Acosta: el posmachismo ya está aquí. El Mundo, 30 de enero de 2009. Disponible en: https://www.elmundo.es/yodona/2009/01/30/actualidad/1233307801.html

Cornejo-Valle, Mónica y Pichardo, J. Ignacio. (2017). La "ideología de género" frente a los derechos sexuales y reproductivos. El escenario español. Cuadernos Pagu (50). Disponible en http://eprints.ucm.es/43862/

Del Águila, RAFAel (2002). ¿De nuevo el fin de las ideologías? En Las ideas políticas del siglo XXI. Ed. por Mellón, Joan Antón. Barcelona: Ariel.

De Miguel, AnA. (2015). Neoliberalismo sexual. Madrid: Ediciones Cátedra.

DillARD, MARIA K. (2013). "Movement/ counter-movement dynamics". En Encyclopedia of Social and Political Movements, compilado por David Snow, Donatella della Porta, Bert Klandermans y Doug McAdam. Oxford: Wiley-Blackwell. Pp.780-783

EL Mundo (4 de marzo de 2013). Un dirigente del PSOE de Huelva dice que Báñez 'estaría mejor haciendo punto de cruz'. Disponible en https://www.elmundo.es/elmundo/2013/03/04/andalucia/1362409708.html

European PaRliamentary Forum, EPF (2018). Restaurar el orden mundial. La visión de extremistas religiosos para movilizar a las sociedades europeas contra los derechos humanos relacionados con la sexualidad y la reproducción. Bruselas: EPF. Disponible en https://www.epfweb.org/sites/default/files/2020-05/rtno_es_web.pdf.

FERNÁNDEZ VÁzQUEZ, GuILlERMo. (2019) España: VOX, ¿arcaísmo o modernidad? En Delle Donne, Franco y Jerez, Andreu (eds). Epidemia Ultra. La ola reacionaria que contagia a Europa. Berlín: Publicación independiente. 
Frachon, Alain y Vernet, Daniel. (2006). La América mesiánica. Los orígenes del neoconservadurismo y las guerras del presente. Barcelona: Paidós

Giddens, Anthony. (1990). Consecuencias de la modernidad. Madrid: Alianza Editorial.

González Cuevas, Pedro Carlos. (2019). VOX. Entre el liberalismo conservador y la derecha identitaria. San Sebastián: La Tribuna del País Vasco.

HALl, STUART. (2014). Sin garantías. Trayectorias y problemáticas en estudios culturales. Popoyan (Colombia): Editorial Universidad del Cauca.

Hernández Castellanos, Donovan. (2019). La extrema derecha: el reto que enfrentamos. Animal Político, 25 de julio de 2019. Disponible en: https://www.animalpolitico.com/blog-invitado/la-extrema-derecha-el-reto-que-enfrentamos/

HuffPost (2019). Vox no apoyará a PP y Ciudadanos si no eliminan el respaldo a la ley de violencia de género. HuffPost, 2 de enero de 2019. Disponible en https://www. huffingtonpost.es/2019/01/02/vox-no-apoyara-a-pp-y-ciudadanos-si-no-eliminan-el-respaldo-a-ley-de-violencia-de-genero_a_23631802/

LA NAción (22 de abril de 2014). Mauricio Macri: "A todas las mujeres les gusta que les digan un piropo, por más que te digan alguna grosería". Disponible en https://www. lanacion.com.ar/buenos-aires/mauricio-macri-dijo-que-las-mujeres-disfrutan-delos-piropos-incluso-de-los-groseros-nid1684215

La Segunda Online (6 de febrero de 2015). Lorenzini: "Hay mujeres que tienen violaciones porque, a lo mejor, tomaron un traguito de más". Disponible en http://www. lasegunda.com/Noticias/Politica/2015/02/991314/Lorenzini-Hay-mujeres-quetienen-violaciones-porque-a-lo-mejor-tomaron-un-traguito-de-mas

LA VANGUARDiA (16 de marzo de 2016). Un concejal del PP de Palafolls cree que Colau "debería estar fregando suelos". Disponible en https://www.lavanguardia.com/local/ barcelona/20160314/40420621269/concejal-pp-palafolls-ada-colau-fregandosuelos.html

Maestre, Romualdo. (2019). Francisco Serrano (Vox) pide "fiscalizar los 2.200 chiringuitos de género" en Andalucìa. ABCandalucía. 7 de enero de 2019. Disponible en https://sevilla.abc.es/andalucia/sevi-francisco-serrano-pide-fiscalizar-2200-chiringuitos-genero-andalucia-201901070813_noticia.html

MARdones, José MARÍA. (1996). Postmodernidad y neoconservadurismo. Reflexiones sobre la fe y la cultura. Madrid: Editorial Verbo Divino.

Martínez, Josefina L. y Burgueño, Cynthia Luz. (2019). Patriarcado y capitalismo. Madrid: Akal.

Meyer, David S. \& Staggenborg, Suzanne. (1996). Movements, countermovements, and the Structure of Political Opportunity. AJS (Vol.101, n6), pp.1628-1660.

NASCimento, ANA. (2014). Un diputado brasileño desata la polémica: "No te voy a violar porque no te lo mereces". elPeriódico.com, 11 de diciembre de 2014. Disponible en https://www.elperiodico.com/es/internacional/20141211/polemica-diputadobrasileno-no-te-voy-a-violar-porque-no-te-lo-mereces-3762343

OAKESHOTT, MichaEL. (2007). La actitud conservadora. Madrid: Sequitur. 
Puleo, Alicia. (1998). Patriarcado. En 10 Palabras clave sobre mujer. Ed. por Amorós, Celia. Estella (Navarra): Editorial Verbo Divino.

Rubio, Alicia. (2017). Cuando nos prohibieron ser mujeres... y nos persiguieron por ser hombres. Para entender cómo nos afecta la ideología de género. Lafactoría.pub.

Sin Embargo (30 de mayo de 2019). Antes de pedir aborto deberían "no abrir las piernas", dice Diputado de Morena en Puebla (VIDEO). Disponible en https://www.sinembargo.mx/30-05-2019/3589229

URBÁn, Miguel. (2019). La emergencia de VOX. Apuntes para combatir a la extrema derecha española. Barcelona: Sylone. Colección Crítica y Alternativa.

URRA, Eugenia, MuÑoz, A. Y PEÑA, J. (2013). El análisis del discurso como perspectiva metodológica para la investigación de salud. Enfermería Universitaria (10, 2), pp. 50-57.

VOX EsPAÑA. Página web del partido Vox España. Disponible en: https://www.voxespana. es /

VOX EsPAÑA. (2018). 100 Medidas para la España Viva. Disponible en https://www.voxespana.es/wp-content/uploads/2019/04/100medidasngal_101319181010040327.pdf

VOX EsTATUTOS. Estatutos del partido, disponibles en https://www.voxespana.es/ Pdf/113-elecciones-Jljdskisd98ujn8UkkJhBn65.pdf 